\title{
PENGARUH PERCEIVED QUALITY TERHADAP CUSTOMER LOYALTY DENGAN PERCEIVED RISK DAN CUSTOMER TRUST SEBAGAI VARIABEL MEDIASI PADA PT. XYZ
}

\author{
Edrick Heriyanto \\ Program Studi Magister Manajemen Universitas Tarumanagara \\ edrick.heriyanto@gmail.com \\ Eko Harry Susanto \\ Program Studi Magister Manajemen Universitas Tarumanagara
}

Masuk : 21-11-2019, revisi : 18-12-2019 diterima untuk diterbitkan : 19-12-2019

\begin{abstract}
The purpose of this study is to examine the influence of perceived quality toward customer loyalty which is mediated by perceived risk and customer trust for PT. XYZ that engaged in chemistry. There are four variables perceived quality as the independent variable, customer loyalty as the dependent variable, and perceived risk and customer trust as mediating variable. The sample was determined by purposive sampling method, the questionnaire was well-collected and was used in data processing using the Structural Equation Modeling (SEM) method with Smart PLS 3.0 program. This analysis was conducted on 115 respondents as customer of PT. XYZ. Based on the result of the study, it was found that perceived quality, perceived risk, and customer trust have influence towards customer loyalty, perceived quality have influence towards perceived risk and customer trust, perceived quality had an indirect effect on customer loyalty via perceived risk and customer trust.
\end{abstract}

Abstrak : Tujuan dari penelitian ini adalah untuk mengetahui pengaruh perceived quality terhadap customer loyalty dengan perceived risk dan customer trust sebagai variabel mediasi pada PT. XYZ yang bergerak di bidang kimia. Variabel yang digunakan dalam penelitian ini adalah perceived quality sebagai variabel independen, customer loyalty sebagai variabel dependen, dan perceived risk dan customer trust sebagai variabel mediasi. Teknik pengambilan sampel dengan menggunakan metode purposive sampling, kuesioner berhasil dikumpulkan dan digunakan dalam pengolahan data menggunakan metode Structural Equation Modeling (SEM) dengan program Smart PLS 3. Analisis ini dilakukan terhadap 115 responden pelanggan PT. XYZ. Bedasarkan hasil penelitian yang dilakukan, ditemukan bahwa perceived quality, perceived risk dan customer trust memiliki pengaruh terhadap customer loyalty, perceived quality memiliki pengaruh terhadap perceived risk dan customer trust, secara tidak langsung perceived quality memiliki pengaruh terhadap customer loyalty melalui perceived risk dan customer trust.

Keywords : perceived quality, perceived risk, customer trust, customer loyalty, and structural equation model (SEM).

\section{Pendahuluan}

Saat ini Indonesia merupakan negara ke empat dalam jumlah penduduk dari seluruh dunia, jumlah penduduk Indonesia akan terus bertambah setiap tahunnya dan tidak akan berhenti untuk bertambah pada tahun-tahun yang akan mendatang. Hal ini dapat dilihat pada data dari Kementrian Perancanaan Pembangunan Nasional Republik Indonesia/Badan Perencanaan Pembangunan Nasional bahwa jumlah penduduk Indonesia akan tumbuh sebesar $28,14 \%$ dari tahun 2010 - 2035 dengan jumlah penduduk sebesar $238.518,8$ juta pada akhir tahun 2010 menjadi 305.652,5 juta pada akhir tahun 2035 . 
Selain jumlah penduduk Indonesia yang ikut meningkat, sektor perekonomian Indonesia juga terus meningkat secara stabil mulai dari tahun 2015 hingga 2017 dan dapat dilihat menurut data dari BPS (Badan Pusat Statistik) mulai dari 2015 pertumbuhan ekonomi hingga 2017 relatif stabil. BPS juga mencatat pertumbuhan ekonomi indonesia pada kuartal I 2018 sebesar 5,06 persen dan pada kuartal II 2018 sebesar 5,27. Pemerintah juga menargetkan pertumbuhan ekonomi pada tahun 2019 sebesar 5,4 persen.

Seiring dengan terus bertumbuhnya jumlah penduduk Indonesia dan perekonomian Indonesia, maka kebutuhan penduduknya juga akan meningkat di mana dalam kehidupan sehari-hari produk yang digunakan masyarakat tidak dapat terlepas dari bahan kimia. Oleh karena itu kebutuhan atas bahan kimia akan terus meningkat untuk memenuhi kebutuhan sehari-hari.

Seiring dengan pertumbuhan penduduk dan perekonomian Indonesia, maka sektor kimia akan terus berkembang di mana Kementerian Perindustrian menargetkan pertumbuhan industri kimia, tekstil dan aneka (IKTA) akan mencapai sebesar 5,4 persen pada tahun 2017. Dirjen IKTA Kemenperin, Achmad Sigit Dwiwahjono mengemukakan, Industri kimia memberikan konstribusi pertumbuhan terbesar jika dibandingkan sektor IKTA lainnya. Apalagi, dengan munculnya Program Jaminan Kesehatan Nasional (JKN) sehingga investor tertarik. Meskipun sektor industri kimia Indonesia terus berkembang, tidak semua perusahaan yang bergerak disektor tersebut sukses dalam mempertahankan pelanggannya, hal ini dapat disebabkan dengan ketatnya sekali pasar kimia dalam hal persaingan maka customer loyalty merupakan faktor yang sangat penting bagi perusahaan untuk bertahan dalam kondisi saat ini.

\section{Kajian Teori}

Consumer behavior, Kotler and Keller (2016), menyatakan adalah studi di mana individu, kelompok dan organisasi melakukan pemilihan, pembelian, menggunakan dan menempatkan produk atau jasa untuk memenuhi keinginan dan juga kebutuhan mereka pada kehidupan sehari-hari.

Customer loyalty, Marakanon dan Panjakajornsak (2017) menyatakan bahwa customer loyalty didefinisikan sebagai komitmen yang dipegang teguh untuk membeli kembali produk atau layanan yang disukai secara konsisten di masa depan, terlepas dari pengaruh dan upaya pemasaran yang berpotensi menyebabkan switching behavior.

Perceived quality, Chen, Tsai and Hsieh (2017) mendefinisikan adalah sebuah penilaian konsumen terhadap sebuah produk atau jasa yang dirasakan dengan membandingkan keunggulan produk atau jasa tersebut dengan produk atau jasa lainnya yang serupa.

Perceived risk, Peter \& Olson (2013) mengemukakan adalah konsekuensi yang tidak diharapkan dan ingin dihindari konsumen saat melakukan pembelian dan menggunakan sebuah produk atau jasa.

Customer trust, Mowen and Minor (2002) adalah suatu perasaan kepercayaan yang bersifat psikologis konsumen terhadap suatu produk atau jasa, baik produk secara fisik ataupun manfaat yang diberikan produk tersebut termasuk pada janji-janji sebuah perusahaan terhadap produk tersebut. 
Kerangka pemikiran yang digunakan dalam penelitian ini adalah:

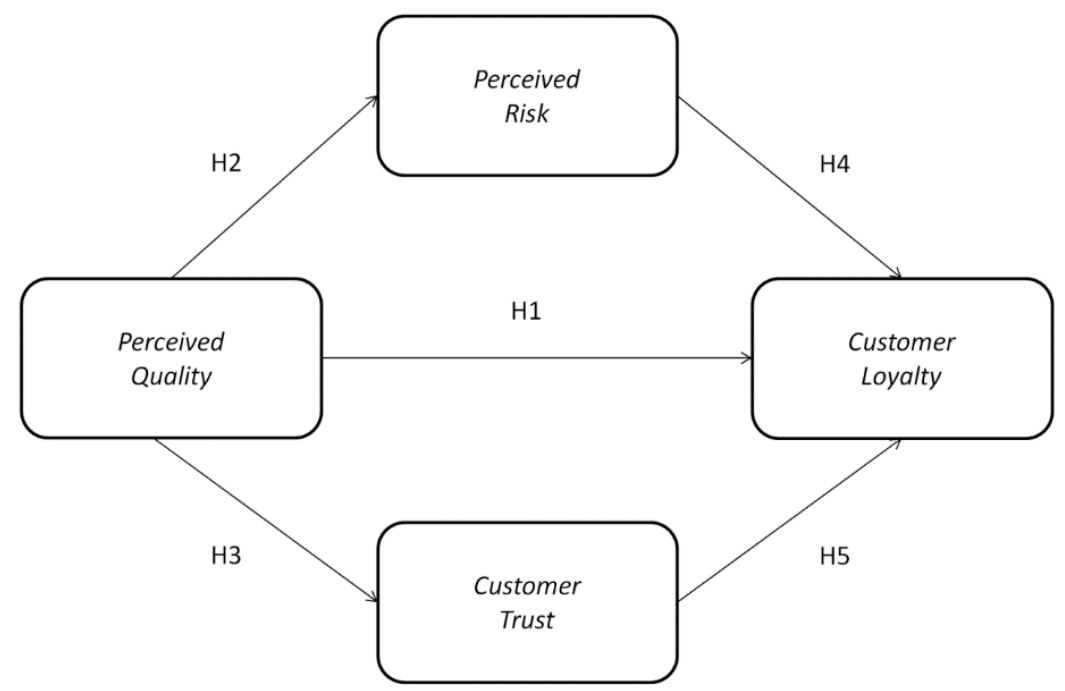

Gambar 1.1 Kerangka Pemikiran

Hipotesis yang dapat dibangun dari gambar diatas adalah:

$\mathrm{H}_{1}$ : Perceived quality berpengaruh positif terhadap customer loyalty

$\mathrm{H}_{2}$ : Perceived quality berpengaruh negatif terhadap perceived risk

$\mathrm{H}_{3}$ : Perceived quality berpengaruh positif terhadap customer trust

$\mathrm{H}_{4}$ : Perceived risk berpengaruh negatif terhadap customer loyalty

$\mathrm{H}_{5}$ : Customer trust berpengaruh positif terhadap customer loyalty

\section{Metodologi}

Penelitian ini menggunakan sumber data primer dengan populasi yang digunakan pada penelitian ini adalah para pelanggan PT. XYZ. Metode pengumpulan data pada penelitian berbentuk pengambilan sampel dari suatu populasi dan menggunakan kuesioner sebagai alat pengumpulan data (Susanto, 2018). Teknik pemilihan sampel yang digunakan dalam penelitian ini adalah purposive sampling yang dipilih melalui kriteria tertentu yang ditetapkan oleh peneliti. Kriteria yang digunakan dalam penelitian ini adalah adalah pelanggan PT. XYZ yang telah membeli produk perusahaan lebih dari satu kali dan pelanggan PT. XYZ yang merupakan end-user. Jumlah sampel yang memenuhi rumus Heir dengan jumlah indicator sebanyak 23, maka minimal jumlah sample dalam penelitian adalah 115 .

Variabel operasional yang digunakan dalam penelitian ini terdiri dari satu variabel independen, satu variabel dependen dan dua variabel mediasi. Variabel independen yang digunakan adalah perceived quality, variabel dependen yang digunakan adalah customer loyalty, dan variabel mediasi yang digunakan adalah perceived risk dan customer trust.

Penelitian ini menggunakan uji factor loading, uji cross loading, uji composite reliability, dan uji average variances extracted, serta uji hipotesis yang terdiri dari uji t dan uji path coefficients.

\section{Hasil Pengolahan Data Outer Loading}

\begin{tabular}{|c|c|}
\hline Variabel & Loadings \\
\hline PQ1 & 0.905 \\
\hline PQ3 & 0.873 \\
\hline PQ4 & 0.846 \\
\hline PQ5 & 0.891 \\
\hline
\end{tabular}


Setelah dilakukan perhitungan ulang dari output di atas, terlihat keseluruhan nilai loading dari indikator yang merefleksikan variabel perceived quality memiliki nilai loading < 0.7 yang berarti seluruh indikator telah berhasil merefleksikan variabel perceived quality, dimana PQ5 merupakan indikator yang terkuat.

\begin{tabular}{|c|c|}
\hline Variabel & Loadings \\
\hline PR1 & 0.883 \\
\hline PR2 & 0.909 \\
\hline PR3 & 0.895 \\
\hline
\end{tabular}

Dari output di atas, terlihat keseluruhan nilai loading dari indikator yang merefleksikan variabel perceived risk memiliki nilai loading $>0.7$ yang berarti seluruh indikator telah berhasil merefleksikan variabel perceived risk, dimana PR2 merupakan indikator yang terkuat.

\begin{tabular}{|c|c|}
\hline Variabel & Loadings \\
\hline CT1 & 0.915 \\
\hline CT2 & 0.907 \\
\hline CT3 & 0.897 \\
\hline
\end{tabular}

Dari output di atas, terlihat keseluruhan nilai loading dari indikator yang merefleksikan variabel customer trust memiliki nilai loading > 0.7 yang berarti seluruh indikator telah berhasil merefleksikan variabel customer trust, dimana CT1 merupakan indikator yang terkuat.

\begin{tabular}{|c|c|}
\hline Variabel & Loadings \\
\hline CL1 & 0.868 \\
\hline CL3 & 0.873 \\
\hline CL4 & 0.876 \\
\hline CL5 & 0.879 \\
\hline CL7 & 0.892 \\
\hline CL9 & 0.843 \\
\hline
\end{tabular}

Setelah dilakukan perhitungan ulang dari output di atas, terlihat keseluruhan nilai loading dari indikator yang merefleksikan variabel customer loyalty memiliki nilai loading < 0.7 yang berarti seluruh indikator telah berhasil merefleksikan variabel customer loyalty, dimana CL7 merupakan indikator yang terkuat.

\section{Composite Reliability}

\begin{tabular}{|c|c|c|c|}
\hline Variabel & $\begin{array}{c}\text { Nilai Composite } \\
\text { Reliability }\end{array}$ & $\begin{array}{c}\text { Standard Composite } \\
\text { Reliability }\end{array}$ & Keputusan \\
\hline Perceived Quality & 0.932 & 0.600 & Reliabel \\
\hline Perceived Risk & 0.924 & 0.600 & Reliabel \\
\hline Customer Trust & 0.932 & 0.600 & Reliabel \\
\hline Customer Loyalty & 0.95 & 0.600 & Reliabel \\
\hline
\end{tabular}

Dari output di atas, terlihat bahwa composite reliability pada variabel perceived quality, perceived risk, customer trust, dan customer loyalty memiliki nilai lebih besar daripada standar composite reliability yang berarti seluruh variabel sudah reliabel dengan standar pengukuran composite reliability. 
AVE

\begin{tabular}{|l|c|c|c|}
\hline \multicolumn{1}{|c|}{ Variabel } & AVE & $\begin{array}{c}\text { Standard Average } \\
\text { Variances Exctracted }\end{array}$ & Keputusan \\
\hline Perceived Quality & 0.773 & 0.500 & Layak \\
\hline Perceived Risk & 0.802 & 0.500 & Layak \\
\hline Customer Trust & 0.822 & 0.500 & Layak \\
\hline Customer Loyalty & 0.761 & 0.500 & Layak \\
\hline
\end{tabular}

Dari output di atas, terlihat bahwa keseluruhan variabel memiliki nilai AVE $>0.5$ yang berarti keseluruhan variabel telah layak dengan standar pengukuran average variances exctracted.

Uji Hipotesis

\begin{tabular}{|l|c|c|l|}
\hline \multicolumn{1}{|c|}{ Konstruk } & Signifikansi & $\begin{array}{l}\text { Path } \\
\text { Coefficients }\end{array}$ & \multicolumn{1}{|c|}{ Keputusan } \\
\hline $\begin{array}{l}\text { Perceived Quality } \\
\text { terhadap Perceived Risk }\end{array}$ & 49.92 & -0.901 & $\begin{array}{l}\text { Perceived quality berpengaruh } \\
\text { signifikan negatif terhadap } \\
\text { perceived risk }\end{array}$ \\
\hline $\begin{array}{l}\text { Perceived Quality } \\
\text { terhadap Customer Trust }\end{array}$ & 57.243 & 0.912 & $\begin{array}{l}\text { Perceived quality berpengaruh } \\
\text { signifikan positif terhadap } \\
\text { customer trust }\end{array}$ \\
\hline $\begin{array}{l}\text { Perceived terality } \\
\text { terhadap Customer Loyalty }\end{array}$ & 5.045 & 0.321 & $\begin{array}{l}\text { Perceived quality berpengaruh } \\
\text { signifikan positif terhadap } \\
\text { customer loyalty }\end{array}$ \\
\hline $\begin{array}{l}\text { Perceived Risk terhadap } \\
\text { Customer Loyalty }\end{array}$ & 6.439 & -0.428 & $\begin{array}{l}\text { Perceived risk berpengaruh } \\
\text { signifikan negatif terhadap } \\
\text { customer loyalty }\end{array}$ \\
\hline $\begin{array}{l}\text { Customer Trust terhadap } \\
\text { Customer Loyalty }\end{array}$ & 2.907 & 0.232 & $\begin{array}{l}\text { Customer trust berpengaruh } \\
\text { signifikan positif terhadap } \\
\text { customer loyalty }\end{array}$ \\
\hline $\begin{array}{l}\text { Perceived Quality } \\
\text { terhadap Customer Loyalty } \\
\text { melalui Perceived Risk }\end{array}$ & 6.323 & 0.212 & $\begin{array}{l}\text { Perceived risk memediasi } \\
\text { pengaruh perceived quality } \\
\text { terhadap customer loyalty }\end{array}$ \\
\hline $\begin{array}{l}\text { Perceived Quality } \\
\text { terhadap Customer Loyalty } \\
\text { melalui Customer Trust }\end{array}$ & 2.904 & 0.386 & $\begin{array}{l}\text { Customer Trust memediasi } \\
\text { pengaruh perceived quality } \\
\text { terhadap customer loyalty }\end{array}$ \\
\hline
\end{tabular}

I. Perceived Quality memiliki pengaruh yang signifikan terhadap perceived risk sebesar 0.901 dengan nilai $t_{\text {value }}<1.6632$ yang berarti semakin tinggi perceived quality, maka akan semakin rendah perceived risk.

II. Perceived Quality memiliki pengaruh yang signifikan terhadap customer trust sebesar 0.912 dengan nilai $t_{\text {value }}<1.6632$ yang berarti semakin tinggi perceived quality, maka akan semakin tinggi customer trust.

III. Perceived Quality memiliki pengaruh yang signifikan terhadap customer loyalty sebesar 0.321 dengan nilai $t_{\text {value }}<1.6632$ yang berarti semakin tinggi perceived quality, maka akan semakin tinggi customer loyalty.

IV. Perceived risk memiliki pengaruh yang signifikan terhadap customer loyalty sebesar 0.428 dengan nilai $t_{\text {value }}<1.6632$ yang berarti semakin tinggi perceived risk, maka akan semakin rendah customer loyalty. 
V. Customer trust memiliki pengaruh yang signifikan terhadap customer loyalty sebesar 0.232 dengan nilai $t_{\text {value }}<1.6632$ yang berarti semakin tinggi customer trust, maka akan semakin tinggi customer Loyalty.

VI. Perceived quality secara tidak langsung memiliki pengaruh yang signifikan terhadap customer loyalty melalui perceived risk sebesar 0.212 dengan nilai $t_{\text {value }}<1.6632$

VII. Perceived quality secara tidak langsung memiliki pengaruh yang signifikan terhadap customer loyalty melalui customer trust sebesar 0.386 dengan nilai $\mathrm{t}_{\mathrm{value}}<1.6632$

\section{Penutup}

Berdasarkan hasil penelitian diatas ditemukan bahwa perceived quality, perceived risk dan customer trust memiliki pengaruh terhadap customer loyalty, perceived quality memiliki pengaruh terhadap perceived risk dan customer trust, secara tidak langsung perceived quality memiliki pengaruh terhadap customer loyalty melalui perceived risk dan customer trust.

Atas hasil yang diperoleh, saran yang dapat diberikan adalah perusahaan memperhatian faktor perceived quality dan customer trust, dikarenakan telah terbukti melalui penelitian yang dilakukan bahwa faktor-faktor tersebut memberikan kontribusi yang berpengaruh dalam menciptakan peningkatan terhadap customer loyalty dan perusahaan memperhatian faktor perceived risk, dikarenakan telah terbukti melalui penelitian yang dilakukan bahwa faktor tersebut memberikan kontribusi yang berpengaruh dalam menciptakan penurunan terhadap customer loyalty.

\section{Daftar Pustaka}

Badan Pusat Statistik. (2013). Proyeksi Penduduk Indonesia 2010-2035. Jakarta-Indonesia : Penerbit Badan Pusat Statistik.

Badan Pusat Statistik. (2019). Berita Resmi Statistik Pertumbuhan Ekonomi Indonesia Triwulan IV-2018, No. 15/02/Th.XXII, 6 Februari 2019. Retrieved November 8, 2019, from https://www.bps.go.id/.

Chen, Han S., Tsai, Bi K., and Hsieh, Chi M. (2017). Determinants of Consumers Purchasing Intentions for Hydrogen Electric Motorcycle. MDPI, 9, 1-12.

Kementerian Perindustrian Republik Indonesia. (2016). Peluang Pengembangan Industri Kimia Nasional Terbuka Lebar. Retrived November 9, 2019, from https://kemenperin.go.id/artikel/15802/Peluang-Pengembangan-Industri-KimiaNasional-Terbuka-Lebar.

Kotler, P., \& Keller, K. L. (2016). Marketing Management. (15 ${ }^{\text {th }}$ Edition). New Jersey, USA: Pearson Education.

Marakanon, Lalinthorn and Vinai. (2017). Perceived Quality, Perceived Risk and Customer Trust Affecting Customer Loyalty of Environmentally Friendly Electronics Products. Kasetsart Journal of Social Sciences, 38, 24-30

Mowen, J. C, \& Minor. M. Minor. (2002). Perilaku Konsumen. Jakarta : Penerbit Erlangga.

Peter, Paul J dan Jerry Olson. (2013). Consumer Behaviour : Perilaku konsumen dan strategi pemasaran $\left(4^{\text {th }}\right.$ ed). Jakarta : Penerbit Erlangga.

Susanto, Eko Harry. (2018). Komunikasi Manusia: Teori dan Praktek Dalam Penyampaian Gagasan ( $1^{\text {st }}$ ed.). Jakarta : Penerbit Mitra Wacana Media. 